\title{
A Positividade e a Negatividade do Trabalho nas Representações Sociais de Adolescentes
}

\author{
Denize Cristina de Oliveira ${ }^{123}$ \\ Universidade do Estado do Rio de Janeiro \\ Frida Marina Fischer \\ Mariana Almeida Amaral \\ Maria Cristina Triguero Veloz Teixeira \\ Universidade de São Paulo \\ Celso Pereira Sá \\ Universidade do Estado do Rio de Janeiro
}

\begin{abstract}
Resumo
O objetivo deste trabalho foi comparar as representações sociais de dois grupos de estudantes adolescentes, respectivamente dos períodos diurno e noturno, sobre o trabalho, a associação trabalho-estudo e o adolescente trabalhador. Participaram da pesquisa 724 estudantes do ensino médio público de São Paulo, de ambos os sexos, entre 14 e 18 anos, trabalhadores e não trabalhadores. A coleta de dados consistiu na técnica de evocações livres, que utilizou os termos indutores "trabalho", "trabalhar e estudar" e "adolescente trabalhador". Foi realizada uma análise estrutural das representações, a partir da qual foram formuladas hipóteses de centralidade dos conteúdos das representações. Entre os principais resultados destacaram-se: a ancoragem do termo "trabalho" em significados concretos do dia-a-dia, entre os estudantes do período noturno; e em conteúdos morais nos dois grupos; o predomínio de elementos centrais negativos associados à relação trabalho-estudo entre os estudantes do período noturno; e a imagem positiva do adolescente trabalhador em ambos os grupos.

Palavras-chave: Representação social; adolescente trabalhador; estudo e trabalho; evocação livre.
\end{abstract}

\section{Positivity and Negativity of the Work in Adolescents' Social Representations}

\begin{abstract}
This research aimed to compare the social representations of adolescents who study during the day and of those who study in the evening concerning three related objects: the work itself, the association between working and studying, and the adolescent who works. The subjects were 724 male and female high school students from 14 to 18 years old, divided into a worker and a non-worker groups. Data were collected using the free evocation method with inductor terms, and the software Evoc helped in the formulation of hypotheses about the centrality of the main contents of each representation. The most important results were: the anchoring by workers of the term "work" in elements of their everyday life; the predominance among workers of negative central elements as to the association between studying and working; the positive image for both groups regarding the adolescent who works.

Keywords: Social representation; adolescent worker; studying and working; free evocation.
\end{abstract}

A preocupação com o trabalho do adolescente vem merecendo especial atenção pela sociedade brasileira e instituições internacionais como a Organização Internacional do Trabalho (OIT). O Programa Internacional do Trabalho IPEC-OIT (1995) ressalta que, somente no Brasil, há 24 programas em desenvolvimento, alguns que tratam do trabalho de crianças e adolescentes em atividades específicas da área rural, plantações de cana, sisal, assim como do subemprego em áreas urbanas.

A legislação brasileira proíbe o trabalho noturno perigoso ou insalubre a menores de 18 anos e qualquer trabalho a menores de 16 anos, salvo nas condições de aprendiz, a partir de 14 anos (Brasil, 1999).

Alguns autores argumentam sobre os aspectos positivos e benéficos da entrada precoce na força de trabalho, no sentido

1'Órgãos financiadores: FAPESP (processo 2000/11431-2); CNPq (processo 52.1981/ 96-4)

${ }^{2}$ Endereço para correspondência: Rua Gal. Ribeiro da Costa, 178, 1201, Leme, Rio de Janeiro,22010 050. Fone: (21)25429385/93071771.E-mail:dco@uerj.br

${ }^{3}$ Agradecimentos aos demais membros da equipe de trabalho: Marcio Lombardi Jr (Bolsistas de Iniciação Científica FAPESP), Roberta Nagai (Bolsista de Treinamento Técnico FAPESP); Prof. Dra. Maria do Rosário Dias de Oliveira Latorre, do Departamento de Epidemiologia da Faculdade de Saúde Pública da USP, e Dra. Sharon Cooper, da $A \&$ M University System, Texas, US A (consultores das análises estatística e epidemiologia). de contribuir para o crescimento como pessoa ou cidadão, incorporando sentimentos de auto-estima e realização à sua personalidade, desde que compativel e equilibrado com seu potencial energético (Forastieri, 1997). No entanto, o trabalho pode tornar-se uma atividade com conseqüências negativas para o jovem quando não pode ser conciliado com outras atividades tão importantes para o adolescente como, por exemplo, o estudo, o lazer e o próprio convívio familiar. Asmus, Suyanna, Ruzani e Meirelles (1996), Dauster (1992), Lima e Câmara (2002) e Neto e Moreira (1998) mostram os múltiplos efeitos negativos do trabalho infanto-juvenil, destacando a desmotivação, o cansaço, a pouca remuneração salarial e os problemas de saúde, entre outros.

Sato (1993) destaca que a penosidade do trabalho está relacionada à falta de controle do trabalhador sobre a atividade laboral, uma vez que esse controle depende da possibilidade do trabalhador intervir na resolução de conflitos que se apresentam no cotidiano. E, ainda, do reconhecimento de um limite subjetivo, que varia de acordo com as condições de trabalho e com o próprio trabalhador, ou seja, quanto, quando e o que é possível agüentar no trabalho. No caso dos trabalhadores jovens, tal controle não está presente, o que é um forte indício de prejuízos causados a sua formação por diversas atividades que exercem. 
Martins, Fischer e Oliveira (2000), Fischer e colaboradores (2003) e Martins e colaboradores (2002), em pesquisa realizada em duas cidades do interior de São Paulo, encontraram resultados que corroboram algumas das consequiências negativas do trabalho infantil e adolescente, destacando-se a falta de experiência no trabalho, a inadequada supervisão, a execução de tarefas perigosas que envolvem riscos à vida e o inadequado conhecimento sobre os riscos do trabalho, além dos débitos acumulados de sono, decorrentes das atividades de trabalho e estudo, uma vez que a perda aguda de sono gera nível elevado de sonolência durante o dia, momentos de desatenção, curtos episódios de sono que passam despercebidos, queda no desempenho e alterações dos estados de ânimo.

Oliveira (2000) e Oliveira, Fischer, Martins, Teixeira e Sá (2001) destacam os riscos psicossociais do trabalho para o adolescente, que consistem, especialmente, no comprometimento da temporalidade do desenvolvimento da criança e do jovem trabalhador, que deixam de vivenciar experiências fundamentais para o seu desenvolvimento psicossocial em momentos nos quais essas experiências seriam fundamentais. Esses autores destacam, ainda, a competição entre trabalho e escola, resultando no abandono precoce da escola, e a exposição a situações e agravos incompatíveis com o estágio de maturação intelectual, emocional e social, que podem ser obscurecidos pela aparente maturação física.

Para análise dessa questão, além da abordagem objetiva dos danos à saúde e ao aproveitamento escolar, igualmente importante é a abordagem das imagens que os atores sociais constroem do trabalho, da relação trabalho-estudo e de si próprios como trabalhadores.

Essas imagens, ou representações, acabam por sustentar as práticas sociais que tendem a priorizar o trabalho sobre o estudo e a manutenção do jovem trabalhador no mercado de trabalho, muitas vezes abandonando a escola precocemente, ainda num momento de escolarização obrigatória. O processo de exclusão escolar se desenvolve a partir da associação do trabalho a valores morais, a um melhor futuro do que aquele reservado ao jovem em função da sua inserção social, ao esforço pessoal e como forma de contornar problemas urbanos, tais como o envolvimento com drogas ilícitas e a marginalidade, conforme observado em estudos desenvolvidos por Martins e colaboradores (2000).

Alves-Mazzotti (1992a, 1992b), em pesquisa desenvolvida sobre as representações sociais de alunos trabalhadores de primeiro grau de uma escola pública, encontrou que os principais motivos apontados pelos jovens para a busca de trabalho foram a possibilidade de consumo (39\%), ocupação de tempo ocioso protegendo-os dos perigos das ruas (33\%), ajudar a família (14\%) e aprendizagem e desenvolvimento $(8 \%)$. Destaca a autora que o fato de estarem trabalhando, terem seu próprio dinheiro, e ajudarem nas despesas da casa, possibilita aos jovens um sentimento de independência, bem como de auto-valorização e respeito, o que contribui para a formação de uma auto-imagem positiva.

Em outros dois trabalhos, Alves-Mazzotti (1994) refere que as representações do trabalho entre os jovens trabalhadores que estudam apresentam, em geral, positividade, vendo-o como atividade necessária ligada ao próprio sustento ou à ajuda à família, e ainda como preparação para o futuro e distração. Afirma a autora que, ao trabalhar, os adolescentes se sentem úteis e com certa independência econômica, o que resulta em uma auto-estima elevada, além de possibilitar associações positivas em relação ao futuro, a partir do esforço que fazem para estudar e trabalhar.

O referencial teórico que embasa esta pesquisa é a Teoria das Representações Sociais (Farr \& Moscovici, 1984; Jodelet, 1989; Moscovici, 1976; Sá, 1996), que tem sido cada vez mais explorada no âmbito da saúde e da educação, especialmente em estudos nos quais importe ter acesso ao conhecimento social que orienta as práticas de uma dada população, ou seja, o conhecimento que ela utiliza para interpretar seus problemas e justificar suas práticas sociais.

A respeito do conceito de representação social, Jodelet (2001) assinala:

As representações sociais devem ser estudadas articulando-se elementos afetivos, mentais e sociais e integrando - ao lado da cognição, da linguagem e da comunicação - a consideração das relações sociais que afetam as representações e a realidade material, social e ideativa sobre a qual elas têm de intervir. (p. 26)

As teorias elaboradas pelas comunidades, que lhes proporcionam uma compreensão do mundo à sua volta, se referem aos mais diversos objetos sociais que pareçam ter alguma importância - real ou imaginada - para a sua existência, identidade, continuidade, etc, como é o caso das questões relacionadas à saúde e, no caso particular deste projeto, o trabalho precoce. Conforme Abric (2001), a representação é um conjunto organizado de opiniões, atitudes, crenças e informações referentes a um objeto ou a uma situação. Uma das teorias que fundamenta a abordagem experimental do estudo da representação social é a teoria do núcleo central proposta por Abric (1994), que permite avaliar a estrutura e a dinâmica das representações sociais.

Para Abric (2001), essa teoria se articula com base na hipótese geral de que toda representação se organiza em torno de um núcleo central que determina a significação e organização da representação. Os elementos centrais da representação são determinados pela natureza do objeto representado e pela relação que o sujeito mantém com esse objeto. São elementos muito estáveis da representação a partir dos quais podem ser criadas ou transformadas as significações de outros elementos constitutivos da mesma e que também determinam a natureza dos vínculos que unem entre si os elementos da representação. Já os elementos periféricos, constituídos por um número maior de idéias acerca do objeto representado, fazem a interface entre o núcleo central e as situações e práticas concretas da população, incorporando as experiências e histórias individuais dos seus membros e se mostrando, assim, não apenas mais sensível à influência do contexto social imediato, mas também mais flexível na orientação dos comportamentos que nele se desenrolam. (Abric, 1994; Oliveira, 1996; Sá, 1996). 
O presente estudo objetivou analisar a estrutura da representação social do trabalho entre adolescentes escolares - elementos centrais, periféricos e intermediários -; comparar as representações sociais de estudantes dos turnos diurno e noturno sobre o trabalho, o trabalho associado ao estudo e o adolescente que trabalha, e discutir o perfil e funções desses elementos para o cotidiano dos jovens.

\section{Método}

\section{Participantes}

O grupo de estudo foi formado pela população de estudantes do ensino médio de uma escola da rede pública do município de São Paulo, totalizando 724 adolescentes dos períodos diurno e noturno, cursando da $1^{\text {a }}$. à $3^{\text {a }}$. série do ensino médio, na faixa etária de 14 a 18 anos, de ambos os sexos.

\section{Procedimentos}

A coleta de dados foi desenvolvida em 2001 e consistiu na aplicação da técnica de evocações livres, mediada por 3 termos indutores - trabalho; trabalhar e estudar; adolescente que trabalha -, a partir dos quais os participantes evocaram as primeiras 5 palavras ou expressões que vinham às suas mentes, na ordem em que elas surgissem na memória (Sá, 1996; Vergès, 1982, 1984). Para a coleta de dados foi utilizado um questionário de auto-resposta, aplicado a grupos de 25 alunos, em sala de aula.

O projeto de pesquisa foi apresentado e aprovado pelo Comitê de Ética da Faculdade de Saúde Pública/USP (Of. COEP/125/ 00). Os participantes do estudo assinaram um "Termo de Consentimento Livre e Esclarecido".

\section{Análise dos Dados}

Para o tratamento dos dados foi utilizado o software Evoc 2000 (Vergès, 2000) e a técnica de distribuição dos termos produzidos num quadrante de 4 casas (Vergès, 1982, 1984).

Para a construção do quadrante foram considerados dois indicadores: a freqüência total das palavras evocadas e sua média simples; a ordem das evocações produzidas, representada por uma média de freqüências ponderadas, calculada atribuindo-se peso 1 às palavras evocadas em primeiro lugar, peso 2 em segundo, e assim sucessivamente até a última palavra evocada. A somatória das freqüências ponderadas e sua divisão forneceu o valor médio da ordem de evocação de cada palavra. Procedeu-se, então, ao cálculo da média geral da ordem de evocação do conjunto de termos produzidos, que serviu de ponto de corte para a construção do quadrante, juntamente com a freqüência média simples do conjunto dos termos. Para a interpretação dos resultados adotou-se a premissa proposta por Abric (1994), Sá (1996) e Oliveira (1996) de que os termos que atendessem, ao mesmo tempo, aos critérios de evocação com maior freqüência e nos primeiros lugares, supostamente teriam uma maior importância no esquema cognitivo do sujeito, ou seja, se configurariam como hipótese de núcleo central da representação social.
Para a construção do quadrante são definidos pelo pesquisador os valores dos eixos x e y. No eixo x, define-se a média simples das freqüências; no y a média das ordens médias ponderadas das evocações. Formado o quadro, considera-se que as palavras que se situam no quadrante superior esquerdo são, muito provavelmente, elementos do núcleo central da representação estudada; aquelas situadas nos quadrantes superior direito e inferior esquerdo são elementos intermediários próximos ao núcleo central; e aquelas localizadas no quadrante inferior direito são elementos mais claramente periféricos (Sá, 1996, 1998).

\section{Resultados e Discussão}

\section{Características da População}

Participaram do estudo 354 alunos do período noturno e 370 do diurno de uma escola pública da cidade de São Paulo localizada na região oeste, sendo 259 não trabalhadores e 111 trabalhadores no período diurno, e 106 não trabalhadores e 248 trabalhadores no período noturno. Do total de alunos estudados, 57,3\% são do sexo masculino e $42,7 \%$ do sexo feminino. Em relação aos hábitos de vida, 10,7\% dos estudantes fumam regularmente e destes, 58,2\% fumam há mais de 1 ano. Entre os que referiram ingestão de bebida alcoólica (63,6\% dos estudados), 50,7\% já esteve de ressaca. Encontramos forte associação entre o hábito de fumar e consumo de bebidas alcoólicas; $95,2 \%$ dos que fumam também bebem $\left(\chi^{2}<0,01\right)$. Praticam atividade física, 85,3\% dos estudantes, sendo o futebol $(35 \%)$ e a dança $(36,9 \%)$ as principais atividades mencionadas.

\section{Configurações da Estrutura das Representações Sociais}

Conforme destacado no método, a construção do quadrante de distribuição das evocações é a técnica de análise que fornece a identificação dos elementos considerados centrais na representação, localizados no quadrante superior esquerdo, e daqueles que desempenham um papel periférico, localizados nos quadrantes superior direito, inferior esquerdo e inferior direito, mais marcadamente os elementos do último quadrante. Vale lembrar que essa distribuição é feita com base em médias simples e ponderadas, portanto a partir de indicadores quantitativos; no entanto, a interpretação desses resultados deve ser feita a partir de dimensões ou categorias construídas com lógica qualitativa e quantitativa, respeitando-se a distribuição dos termos nos quadrantes.

Dessa forma, os resultados apresentados serão discutidos de forma comparativa entre os turnos da manhã e noite, a partir da localização dos elementos/categorias nos respectivos quadrantes, e das funções desses elementos na representação que essa localização aponta.

A seguir, serão apresentadas as Figuras 1 e 2 nas quais se pode observar a distribuição das palavras evocadas ao termo "trabalho", conforme a freqüência e a ordem média de evocação.

Observa-se nas Figuras 1 e 2 que os elementos constituintes do núcleo central da representação social do trabalho, presentes no 


\begin{tabular}{|c|c|c|c|c|c|c|}
\hline O.M.E & $<2$ & & & & & \\
\hline Freq. Me & & Freq & $\mathrm{OME}$ & & Freq & $\mathrm{OME}$ \\
\hline & Dinheiro & 205 & 2,59 & Cansativo & 94 & 3,021 \\
\hline & Responsável & 134 & 2,142 & Independência & 75 & 3,093 \\
\hline$\geq 40$ & Essencial & 104 & 2,058 & Experiência & 41 & 3,122 \\
\hline & Bom & 85 & 2,459 & & & \\
\hline & Muita Responsabilidade & 57 & 1,772 & & & \\
\hline & Necessidade & 45 & 2,511 & & & \\
\hline & Esforço & 26 & 2,577 & Futuro & 38 & 3,421 \\
\hline & Dedicação & 21 & 2,762 & Obrigação & 34 & 3,029 \\
\hline$<40$ & Difícil & 19 & 2,737 & Ruim & 34 & 3,029 \\
\hline & Próprio Dinheiro & 14 & 2,00 & Amadurecimento & 29 & 3,621 \\
\hline & Dever & 12 & 2,75 & Relacionamento & 29 & 3,448 \\
\hline & Compromisso & 11 & 2,818 & Aprender & 22 & 3,591 \\
\hline & & & & Gostar & 22 & 3,273 \\
\hline & & & & Diversão & 17 & 3,412 \\
\hline & & & & Longe Rua & 17 & 3,059 \\
\hline & & & & Horário & 16 & 3,00 \\
\hline & & & & Comprar Coisas & 15 & 3,933 \\
\hline & & & & Recompensador & 15 & 3,533 \\
\hline & & & & Cotidiano & 14 & 3,714 \\
\hline & & & & Respeito & 14 & 3,857 \\
\hline & & & & Chefe & 13 & 3,308 \\
\hline & & & & Estressante & 12 & 3,25 \\
\hline & & & & Família & 12 & 3,333 \\
\hline
\end{tabular}

Figura 1. Estrutura da representação social do "trabalho" no grupo de adolescentes do período diurno, pela freqüência média e ordem média de evocação (OME). São Paulo, 2002. ( $n$ sujeitos $=370 ; n$ palavras=1732)

\begin{tabular}{|c|c|c|c|c|c|c|}
\hline \multirow{2}{*}{$\frac{\text { O.M.E }}{\text { Freq. Me }}$} & \multicolumn{3}{|c|}{$<2,9$} & \multicolumn{3}{|c|}{$\geq 2,9$} \\
\hline & & req & OME & & Freq & OME \\
\hline \multirow{9}{*}{$\geq 55$} & Dinheiro & 182 & 2,4 & Cansativo & 77 & 2,9 \\
\hline & Responsável & 88 & 1,9 & Futuro & 62 & 3,1 \\
\hline & Essencial & 81 & 2,1 & & & \\
\hline & Muita Responsabilidade & 67 & 2,2 & & & \\
\hline & Bom & 64 & 2,5 & & & \\
\hline & Esforço & 52 & 2,6 & Amadurecimento & 40 & 3,4 \\
\hline & Independência & 52 & 2,7 & Experiência & 39 & 3 \\
\hline & Necessidad & 44 & 2,1 & Aprender & 34 & 3,4 \\
\hline & Acordar cedo & 25 & 2,3 & Relacionamento & 28 & 4,1 \\
\hline \multirow[t]{2}{*}{$<55$} & Próprio dinheiro & 22 & 2,5 & Obrigação & 21 & 3,1 \\
\hline & & & & Aborrecimento & 20 & 4,0 \\
\hline
\end{tabular}

Figura 2. Estrutura da representação social do "trabalho" no grupo de adolescentes do período noturno, pela freqüência média e ordem média de evocação (OME). São Paulo, 2002. ( $n$ sujeitos=354; $n$ palavras=1676)

quadrante superior esquerdo, foram semelhantes entre os grupos da manhã e da noite. Essa semelhança foi definida por termos positivos associados ao trabalho, e que enfatizam as funções de crescimento, de estimulação da criatividade e de aprovação social derivadas dessa atividade, além de associá-la a suas conseqüências diretas ou indiretas, como "dinheiro" e "responsabilidade".

A diferença observada no quadrante superior esquerdo foi a presença da evocação "necessidade", o que a coloca como central na representação do trabalho apenas no grupo do período diurno, apontando para um conteúdo que associa a presença do trabalho às condições desfavoráveis de vida de forma mais destacada nesse grupo. A necessidade econômica não foi um elemento central da representação de trabalho no grupo do noturno, uma vez que se localiza no quadrante inferior esquerdo, apontando a maior importância dada a outras funções do trabalho, como aquelas relacionadas com o desenvolvimento humano e a aprovação pessoal, expressas nas evocações “essencial”, ‘bom”, "'responsável”, presentes no quadrante superior esquerdo.

Um elemento negativo central, e compartilhado por ambos os grupos, referiu-se a "muita responsabilidade", que reflete a 
falta de experiência no trabalho, o excesso de tarefas e, especialmente, exigências psicossociais incompatíveis com o momento de desenvolvimento do jovem trabalhador, e geradoras de estresse psicológico.

Observa-se nesses resultados a significação fundamentalmente positiva que o trabalho assume para esses dois grupos de adolescentes, significação essa que se divide entre a possibilidade de emancipação econômica (expressa na palavra "dinheiro") e psicoemocional (expressa nas palavras "responsável", "bom", "essencial").

Em relação aos elementos periféricos, localizados no segundo e terceiro quadrantes, observa-se que apresentam uma maior variedade de termos em comparação com os do primeiro quadrante. No que diz respeito aos elementos periféricos próximos, observa-se que tanto num grupo como no outro aparece o elemento "cansativo", que está relacionado com as conseqüências imediatas derivadas da prática do trabalho. No entanto, chama a atenção que o termo "acordar cedo" presente no grupo do período noturno, e os termos "dificil", "dedicação", "dever" e "compromisso" do grupo do período diurno, expressem significados diferentes. Acredita-se que o grupo da noite evoca a palavra "acordar cedo" em função da própria prática social vivenciada, uma vez que na maioria são trabalhadores, enquanto que o grupo do diurno refere-se ao trabalho com termos mais abstratos e distantes do cotidiano.

Os elementos periféricos distantes associados ao trabalho, quadrante inferior direito, diferem entre os dois grupos, tanto em relação ao número de termos aí presentes, quanto ao conteúdo que expressam. No grupo do período diurno a maioria dos termos expressou positividade em relação ao trabalho, referindo-se aos ganhos imediatos relacionados com a independência pessoal e o lazer, que nem sempre são possíveis quando o adolescente não ganha seu próprio dinheiro ("gostar", "diversão", "longe rua", "comprar coisas", "recompensador"), diferentemente do grupo do período

\begin{tabular}{|c|c|c|c|c|c|c|}
\hline \multirow{2}{*}{$\frac{\text { O.M.E }}{\text { Freq. Me }}$} & \multicolumn{3}{|c|}{$<2,9$} & \multicolumn{3}{|c|}{$\geq 2,9$} \\
\hline & & Freq & OME & & Freq & OME \\
\hline & Cansativo & 220 & 2,255 & Futuro & 55 & 3,364 \\
\hline & Muita Responsabilidade & 110 & 2,645 & Dinheiro & 40 & 3,875 \\
\hline & Difícil & 92 & 2,152 & Falta de Tempo & 34 & 3,324 \\
\hline & Bom & 70 & 2,729 & & & \\
\hline$\geq 32$ & Ruim & 70 & 2,357 & & & \\
\hline & Essencial & 63 & 2,397 & & & \\
\hline & Necessidade & 56 & 2,786 & & & \\
\hline & Responsável & 49 & 2,735 & & & \\
\hline & Sono & 48 & 2,792 & & & \\
\hline & Estressante & 44 & 2,705 & & & \\
\hline & Conciliar & 21 & 2,381 & Esforço & 30 & 2,933 \\
\hline & Conhecer & 17 & 2,353 & Amadurecimento & 23 & 3,609 \\
\hline & Força de Vontade & 15 & 2,6 & Obrigação & 23 & 3 \\
\hline & Desmotivado & 12 & 2,833 & Aprender & 21 & 2,952 \\
\hline$<32$ & Organização & 8 & 2,75 & Experiência & 20 & 3,45 \\
\hline & & & & Tempo & 20 & 3,2 \\
\hline & & & & Atrapalha o Estudo & 18 & 3,056 \\
\hline & & & & Independência & 15 & 3,867 \\
\hline & & & & Preguiça & 15 & 3,333 \\
\hline & & & & Correria & 14 & 3,143 \\
\hline & & & & Relacionamento & 14 & 3,143 \\
\hline & & & & Pique & 12 & 3,25 \\
\hline & & & & Determinação & 11 & 3,182 \\
\hline & & & & Longe Rua & 11 & 3,545 \\
\hline & & & & Ajudar a Família & 10 & 3,2 \\
\hline & & & & Dever & 10 & 3,3 \\
\hline & & & & Aborrecimento & 9 & 3,444 \\
\hline & & & & Cotidiano & 9 & 3,333 \\
\hline & & & & Educa & 9 & 3,222 \\
\hline & & & & Vontade & 9 & 3,556 \\
\hline & & & & Diversão & 8 & 3,875 \\
\hline & & & & Gostar & 8 & 3,25 \\
\hline
\end{tabular}

Figura 3. Estrutura da representação social do "trabalho" a partir do termo indutor "trabalhar e estudar", no grupo de adolescentes do período diurno, pela freqüência média e ordem média de evocação (OME). São Paulo, 2002. $(n$ sujeitos $=370 ; n$ palavras $=1754)$ 


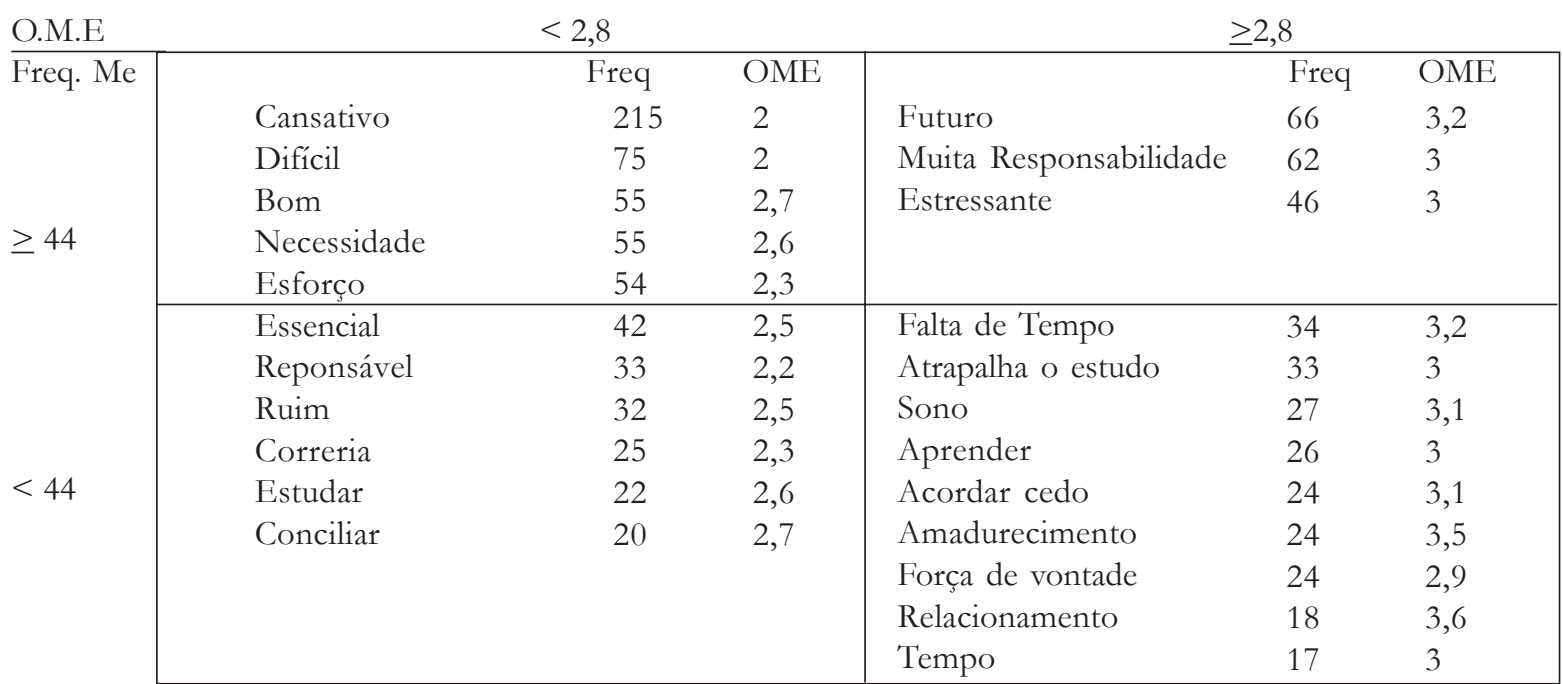

Figura 4. Estrutura da representação social do "trabalho" a partir do termo "trabalhar e estudar", no grupo de adolescentes do período noturno, pela freqüência média e pela ordem média de evocação (OME). São Paulo, 2002. ( $n$ sujeitos $=354 ; n$ palavras=1604)

noturno, que representa o trabalho a partir de ganhos a longo prazo, no sentido de prepará-los para a vida e para o mercado de trabalho, ou seja, aquelas funções do trabalho relacionadas com o desenvolvimento da criatividade e com o aprendizado, expressas nas evocações "experiência", "aprender".

As Figuras 3 e 4 mostram as evocações relacionadas com o termo indutor "trabalhar e estudar", retratando as representações do trabalho quando vistas a partir da dupla jornada trabalho e estudo.

Ao comparar as evocações localizadas nos núcleos centrais da representação social do objeto representado, observa-se que as referências negativas associadas à dupla jornada representada pelas atividades de trabalho e estudo foram muito mais freqüentes no grupo da noite do que no grupo da manhã. No grupo da manhã houve, em termos quantitativos, maior número de evocações que apontam elementos negativos do trabalho. No entanto, acredita-se que muitas dessas evocações não estão diretamente ancoradas à prática desse grupo, na medida em que são, na maioria, não trabalhadores, e sim a conteúdos socialmente veiculados, nas conversas cotidianas, na mídia, sobre as vivências de outros adolescentes que trabalham.

Já no grupo da noite observa-se a palavra "esforço", que é específica do núcleo central desse grupo, apontando para um significado estreitamente relacionado com a conciliação do estudo e do trabalho, e que se refere, ao mesmo tempo, a um atributo pessoal necessário para suportar a dupla jornada, e também a reafirmação da dureza dessas atividades. Essa mesma evocação aparece apenas como elemento periférico na análise do grupo diurno.

Observa-se em diversos estudos que, embora represente um enorme sacrifício o fato de estudar e trabalhar, esses adolescentes desejam prosseguir seus estudos e são vítimas dos efeitos negativos desta dicotomia. Autores como Mielnik (1987) e Pinheiro (1999) referem os baixos salários, poucas horas de sono, menor tempo para recreação e lazer, e redução do tempo para o estudo, dificuldades para se alimentar, desinteresse pelo estudo. No trabalho desenvolvido por Pinheiro (1999) a necessidade econômica aparece como justificativa para o trabalho para $39 \%$ do total da população de jovens estudada, seguida pela independência financeira, com 31,2\%. Em terceiro lugar ficam os motivos ligados ao prazer de trabalhar, ao amadurecimento e perspectivas de um futuro melhor.

Os dois grupos evocaram a palavra "futuro" como um dos elementos positivos decorrentes da associação trabalho-estudo, associando a concomitância das duas atividades ao desenvolvimento de experiência que lhes permita ascender em uma carreira profissional, além de representar a possibilidade de melhor qualidade de vida e superação da sua atual condição de classe.

No grupo da manhã observa-se nos termos "futuro", "dinheiro", "conhecer" um predomínio de aspectos positivos nos elementos periféricos próximos do núcleo central. Porém destaca-se que, embora existam essas avaliações positivas, os jovens evocaram termos que sinalizam sua rejeição à dupla jornada estudo-trabalho, como por exemplo, na palavra "desmotivado".

Assim como no termo trabalho, o grupo da noite evocou palavras que expressam as dificuldades que enfrentam ao ter que estudar e trabalhar ao mesmo tempo, o que foi expresso nos termos "muita responsabilidade", "estressante", "ruim", "correria" e "conciliar".

Ao comparar os termos evocados que participam da periferia distante observa-se que existe, tanto num grupo quanto no outro, elementos positivos e negativos, embora o número de evocações do grupo da manhã tenha sido maior.

Para integrar a discussão geral da representação da relação estudar e trabalhar em ambos os grupos sugere-se refletir sobre as colocações de Flament:

$\mathrm{Na}$ realidade, a periferia da representação serve de pára-choque entre uma realidade que a questiona e um núcleo central que não deve mudar facilmente. Os desacordos da realidade são absorvidos pelos esquemas periféricos, que, assim, asseguram a estabilidade (relativa) da representação. (Flament, 2001, p. 178)

Essa função de pára-choque, destacada por Flament (2001), pode ser observada nas evocações tanto positivas quanto negativas presentes 
no quadrante inferior direito. Parece que esses elementos, que alguns autores chamam de esquemas, para parte do grupo de adolescentes estudados, não entraram em antagonismo a ponto de mudar a representação do trabalho e da sua relação com o estudo. Parece que os elementos periféricos suportam as múltiplas discordâncias da alternância do trabalho com o estudo, por um lado, porque o trabalho contribui para o amadurecimento pessoal, possibilita novas experiências e a independência econômica, e, por outro, atrapalha o estudo, gera aborrecimentos, representa uma obrigação, e compete com o tempo destinado ao estudo.
Cabe apontar que, nesta pesquisa, é provável que a prática social dos adolescentes tenha desencadeado essas representações sociais, uma vez que o grupo da noite é formado em sua quase totalidade por trabalhadores, e o da manhã, em grande parte, por não trabalhadores. Daí a importância do contexto social no qual eles estão inseridos, onde predomina a necessidade econômica e a contribuição necessária para a renda familiar, como já descrito em trabalho anterior (Kinney, 1993).

Nas Figuras 5 e 6 observam-se as palavras evocadas a partir do termo indutor "adolescente que trabalha" em ambos os grupos.

\begin{tabular}{|c|c|c|c|c|c|c|}
\hline \multirow{2}{*}{$\frac{\text { O.M.E }}{\text { Freq. Me }}$} & \multicolumn{3}{|c|}{$<2,9$} & \multicolumn{3}{|c|}{$\geq 2,9$} \\
\hline & & req & OME & & Freq & OME \\
\hline \multirow{9}{*}{$\geq 38$} & Responsável & 170 & 2,071 & Dinheiro & 80 & 3,275 \\
\hline & Independência & 107 & 2,832 & Cansativo & 64 & 3,25 \\
\hline & Bom & 99 & 2,222 & Futuro & 42 & 3,024 \\
\hline & Necessidade & 87 & 2,23 & & & \\
\hline & Amadurecimento & 53 & 2,83 & & & \\
\hline & Ruim & 33 & 2,545 & Ajudar a Família & 28 & 3,143 \\
\hline & Essencial & 31 & 2,548 & Longe Rua & 27 & 3 \\
\hline & Esforço & 26 & 2,654 & Próprio Dinheiro & 27 & 3,222 \\
\hline & Experiência & 26 & 2,885 & Atrapalha o Estudo & 26 & 3,115 \\
\hline \multirow[t]{11}{*}{$<38$} & Muita Responsabilidade & 24 & 2,583 & Diversão & 22 & 3,727 \\
\hline & Inteligência & 15 & 2,067 & Estressante & 22 & 3,636 \\
\hline & Falta de Tempo & 14 & 2,786 & Difícil & 19 & 3,263 \\
\hline & Ajuda & 13 & 2,846 & Aprender & 18 & 3,111 \\
\hline & & & & Obrigação & 18 & 2,944 \\
\hline & & & & Vontade & 17 & 3,235 \\
\hline & & & & Dedicação & 16 & 3,375 \\
\hline & & & & Esperto & 15 & 3,267 \\
\hline & & & & Determinação & 13 & 2,923 \\
\hline & & & & Comprar Coisas & 12 & 3,833 \\
\hline & & & & Conhecer & 11 & 3,909 \\
\hline
\end{tabular}

Figura 5. Estrutura da representação social do trabalho a partir do termo "adolescente que trabalha" no grupo de adolescentes do período diurno, pela freqüência média e pela ordem média de evocação (OME). São Paulo, 2002. (n sujeitos $=370 ; n$ palavras $=1726$ )

\begin{tabular}{|c|c|c|c|c|c|c|}
\hline \multirow{2}{*}{$\frac{\text { O.M.E }}{\text { Freq. Me }}$} & \multicolumn{3}{|c|}{$<2,8$} & \multicolumn{3}{|c|}{$\geq 2,8$} \\
\hline & & req & OME & & Freq & $\mathrm{OME}$ \\
\hline \multirow{9}{*}{$\geq 45$} & Responsável & 119 & 2,2 & Independência & 88 & 3 \\
\hline & Amadurecimento & 80 & 2,7 & Futuro & 69 & 3 \\
\hline & Necessidade & 79 & 2,2 & Próprio dinheiro & 48 & 3 \\
\hline & Bom & 66 & 2,4 & & & \\
\hline & Dinheiro & 48 & 2,7 & & & \\
\hline & Esforço & 45 & 2,1 & & & \\
\hline & Falta de tempo & 42 & 2,7 & Ajudar a família & 43 & 3 \\
\hline & Muita Responsabilidade & 42 & 2,5 & Cansativo & 39 & 3,1 \\
\hline & Experiência & 30 & 2,7 & Comprar coisas & 27 & 2,9 \\
\hline \multirow[t]{4}{*}{$<45$} & Longe rua & 24 & 2,7 & Estressante & 21 & 3,1 \\
\hline & Aprender & 21 & 2,4 & Respeitado & 21 & 2,9 \\
\hline & Atrapalha o estudo & 20 & 2,4 & Difícil & 18 & 2,9 \\
\hline & Exploração & 17 & 2,4 & & & \\
\hline
\end{tabular}

Figura 6. Estrutura da representação social do trabalho a partir do termo "Adolescente que trabalha" no grupo de adolescentes do período noturno, pela freqüência média e pela ordem média de evocação (OME). São Paulo, 2002. ( $n$ sujeitos $=354 ; n$ palavras $=1579$ ) 
Observa-se nos quadrantes superiores esquerdos das Figuras 5 e 6 que, tanto num grupo quanto no outro, a maioria dos elementos evocados foram positivos ("responsável", "independência", "bom”, "amadurecimento"). São elementos que apontam necessidades sociais e psicoemocionais próprias da adolescência, e que podem ser conseqüentes ao trabalho, como apontado por Gomes (1987). Para os jovens, esses elementos funcionam como atributos que lhes conferem um status semelhante ao de um adulto. As hipóteses de núcleo central da representação social do adolescente que trabalha permitem inferir que o princípio organizador do termo foi positivo. No entanto, uma das evocações em ambos os grupos expressa um componente negativo que pode ser avaliado como estranho ao conjunto de todos os outros aspectos positivos: é o caso da palavra necessidade. A mesma evidencia a relação da imagem do adolescente que trabalha com as dificuldades econômicas vivenciadas pelos mesmos.

Em relação às hipóteses de núcleos periféricos próximos, novamente a positividade em torno da imagem do jovem trabalhador é verificada, só que alguns elementos já expressam desacordos em relação ao núcleo central, como por exemplo, as palavras "cansativo", "muita responsabilidade", "ruim" e "falta de tempo" presentes no grupo da manhã e, no grupo da noite, elementos como "falta de tempo", "muita responsabilidade", "atrapalha o estudo" e "exploração". Esses desacordos entre os conteúdos periféricos da representação são o espelho da realidade social que os adolescentes vivem e que, por estarem na periferia, conseguem absorver as discrepâncias sem mudar a representação positiva do trabalho. Chamou a atenção o fato de que no grupo do período noturno, diferentemente do outro grupo, apareceu o termo "exploração", que evidencia a realidade desses adolescentes submetidos ao trabalho sem garantias empregatícias, o que já vem sendo denunciado por meio de inúmeros trabalhos (Kassouf, Mckee \& Mossialos, 2001; Robazzi, Cano \& Fávero, 1996).

No que diz respeito à hipótese de periferia distante da representação social, chama a atenção que no grupo do período diurno foram apontados mais elementos positivos do que negativos, enquanto que no grupo do noturno esses elementos ficaram equilibrados. Observa-se que os elementos positivos do grupo do período noturno estão dicotomizados entre a necessidade de identificação com o adulto (termo "respeitado") e o ingresso no mercado de consumo e a contribuição com a renda familiar ("ajudar a familia" e "comprar coisas"). Já os elementos negativos comportam aspectos das práticas sociais vivenciadas ("cansativo", "estressante" e "difícil").

Observa-se que nos elementos periféricos distantes, tanto de um grupo quanto do outro, a imagem do adolescente que trabalha é racionalizada em função da prática real desses jovens, que dividem seu tempo entre trabalho e estudo. Essa racionalização faz parte da representação, comportando as contradições dessa divisão, ao mesmo tempo em que é estruturada por elementos concordantes positivos.

\section{Considerações Finais}

Os elementos que conformam as hipóteses de núcleo central das representações sociais do trabalho e das imagens associadas ao adolescente que trabalha foram, tanto no grupo de estudantes do período diurno quanto do noturno, predominantemente positivos, organizando-se em torno das categorias amadurecimento e função moral do trabalho. Um elemento considerado negativo em ambos os núcleos centrais inclui-se na categoria "muita responsabilidade". Quando a imagem do "adolescente que trabalha" é focada observa-se o elemento "necessidade", que pode ser avaliado tanto no sentido negativo (sobreviver, falta de dinheiro) quanto no positivo (ajudar a familia). Infere-se que para esses sujeitos o trabalho, no sentido moralmente associado ao termo, é visto como algo que dignifica o ser humano e que o faz crescer. No entanto, quando esse trabalho é contraposto ao estudo (termo indutor "trabalhar e estudar'), outros elementos negativos passam a ser compartilhados.

Ao enfocar a representação do trabalho a partir da relação estabelecida entre o trabalho e o estudo, observa-se o reflexo do cotidiano e das práticas nas representações dos adolescentes, revelando núcleos centrais distintos e, portanto, representações diferentes nos dois grupos, conforme definido na teoria do núcleo central. (Abric, 1994; Sá, 1996). Acredita-se que a emergência de dimensões negativas do trabalho aparece pelo fato de o termo estar diretamente relacionado com as dificuldades enfrentadas pelos sujeitos ao conciliar o estudo com o trabalho, o que, muitas vezes, os leva a abandonar a escola, pressionados pelo horário, pelo estresse e pela sobrecarga de atividades. Os elementos negativos fizeram parte de categorias como "cansativo", "difícil", "muita responsabilidade" e "perdas". Quando foram evocados elementos positivos, isso foi feito reforçando o sentido da moral social atribuída ao trabalho.

Teoricamente, um dos papéis desempenhados pelos elementos periféricos de uma representação social é contextualizar, na prática, o objeto que está sendo representado. Esta contextualização nem sempre coincide com os elementos do núcleo central e, no caso deste estudo são discordantes. Na periferia apareceram diversos elementos negativos, mostrando o cotidiano do adolescente ao tentar conciliar o trabalho com o estudo.

Infere-se, assim, que os conteúdos positivos encontrados nos núcleos centrais dos três termos analisados são altamente compartilhados pelos grupos e que a dissensão está presente somente na periferia, onde os posicionamentos são heterogêneos e determinados pela prática social. Essencialmente, deduz-se que a representação do trabalho durante a adolescência, mesmo quando associado ao estudo, é positiva e reproduz um discurso moral do trabalho; no entanto a presença de dissenso na periferia da representação aponta, por um lado, para uma acomodação da representação às práticas, e por outro reflete as pressões exercidas sobre a representação por essas mesmas práticas, no sentido da sua mudança. 


\section{Referências}

Abric, J. C. (1994). Pratiques sociales et représentations. Paris: Presses Universitaires de France. Abric, J. C. (2001). O estudo experimental das representações sociais. Em D. Jodelet (Org.), As representaçôes sociais (pp. 155-172). Rio de Janeiro: EdUERJ.

Alves-Mazzotti, A. J. (1992a). Meninos de rua e meninos na rua: Estrutura e dinâmica familiar. Em A. Fausto \& R. Cervini (Orgs.), O trabalho e a rua: Crianças e adolescentes no Brasil urbano dos anos 80 (pp. 125-149). São Paulo: Cortez.

Alves-Mazzotti, A. J. (1992b). Trabalho infanto-juvenil: Representações de meninos trabalbadores, seus pais, professores e empregadores. Relatório de Pesquisa, CNPq.

Alves-Mazzotti, A. J. (1994). Do trabalho à rua: Uma análise das representações sociaisproduridas por meninos trabalhadores e de rua. Rio de Janeiro: Diadorim/UFRJ/CFCH.

Asmus, C. I. R. F., Suyanna, L. B., Ruzani, M. H. \& Meirelles, Z. V. (1996). Riscos ocupacionais na infância e na adolescência: Uma revisão. Jornal de Pediatria, 72, 203 208.

Constituição da República Federativa do Brasil (1999). Imprensa Oficial do Estado de São Paulo, promulgada em 5 de outubro de 1999 - capítulo II. Art. 7. 7-8. (4 ed.). Brasilia,DF.

Dauster, T. (1992). Uma infância de curta duração: Trabalho e escola. Cadernos Pesquisa, 82, 31-36.

Doise, W., Clemence, A. \& Lorenzi-Cioldi, F. (1992). Représentations sociales et analyse de données. Grenoble: Presse Universitaire de Grenoble.

Farr, R. M. \& Moscovici, S. (1984). Social representations. Cambridge: Cambridge University Press.

Fischer, F. M., Martins, I. S., Oliveira, D. C., Teixeira, L. R., Latorre, M. R. D. \& Cooper, S. (2003). Occupational accidents among middle and high school students of the state of São Paulo, Brazil. Revista de Saúde Pública, 37, 351-356.

Flament, C. (2001).Estrutura e dinâmica das representações sociais. Em D. Jodelet(Org), As representações sociais (pp. 173-186). Rio de Janeiro: EdUERJ.

Forastieri, V. (1997). Children at work: Health and safety risks. Geneva: International Labour Office.

Gomes, S. M. T.A. (1987). O adolescente e a força de trabalho. Jornal de Pediatria, 64, 139142.

Jodelet, D. (1989). Folies et représentations sociales. Paris: PUF.

Jodelet, D (2001). Representações sociais: Um domínio em expansão. Em D. Jodelet (Org.), As representacõoes sociais (pp. 17-44). Rio de Janeiro: EdUERJ.

Kassouf, A. L., Mckee, M. \& Mossialos, E. (2001). Early entrance to the job market and its effect on adult health: Evidence from Brazil. Health Policy and Planning, 16, 21- 28.

Kinney,J. A. (1993). Health hazards to children in the service industries. American Journal of Industrial Medicine, 24, 291-300.

Lima, M. I. M. \& Câmara, V. M. (2002). Uma metodologia para avaliar e ampliar o conhecimento de adolescentes do ensino fundamental sobre acidentes de trabalho. Cadernos de Saúde Pública, 18, 115-120.

Martins, I. S., Fischer, F. M. \& Oliveira, D. C. (Orgs.) (2000). Relatório final do Projeto: Saúde, Educação e Trabalho nos Municípios de Monteiro Lobato e Santo Antônio do Pinhal. São Paulo: FSP/FAPESP.

Martins, I. S., Fischer, F. M, Oliveira, D. C., Teixeira, L. R., Costa, L. A. R., Marinho, S. P., Perestrelo, J. P. P. \& Latorre, M. R. D. (2002). Crescimento e trabalho de estudantes de ensino fundamental e médio em São Paulo, Brasil. Revista de Saúde Pública, 36,1925.
Mielnik, I. (1987). O adolescente, a escola e o trabalho. Pediatria Moderna, 22, 278-291.

Moliner, P. (1994). Les méthodes de répérage et d’identification du noyau des représentations sociales. Em C. Guimelli (Org.), Structures et transformations des représentations sociales (pp. 199-232). Neuchâtel: Delachaux et Niestlé.

Moscovici, S. (1976). L a Psychanalyse son image et son public. Paris: Presses Universitaires de France.

Neto, O. C. \& Moreira, M. R. (1998). Trabalho infanto-juvenil: Motivações, aspectos legais e repercussão social. Cadernos de Saúde Pública, 14, 437-441.

Oliveira, D. C. (1996). A promoção da saúde da criança: Análise das práticas cotidianas através do estudo de representações sociais. Tese de Doutorado não-publicada, Curso de PósGraduação em Saúde Pública, Faculdade de Saúde Pública da Universidade de São Paulo. São Paulo, SP.

Oliveira, D. C. (2000). Caracterização das condições de educação. Em I. S. Martins, D. C. Oliveira \& F. M. Fischer (Orgs.), Relatório Final da Pesquisa Saúde, educação e trabalho nos municípios de Monteiro Lobato e Santo Antonio do Pinbal - São Paulo. São Paulo: FSP/ USP.

Oliveira, D. C., Fischer, F. M., Martins, I. S., Teixeira, L. R. \& Sá, C. (2001). Futuro e Liberdade: $\mathrm{O}$ trabalho e a instituição escolar nas representações sociais de adolescentes. Revista Estudos de Psicologia, 6, 245-258.

Organização Internacional do Trabalho (1995). Programas de ação. 1994/1995. Brasilia: Ed. IPEC/OIT.

Pinheiro, A. B. (1999). O trabalho precoce em adolescentes matriculados em escolas municipais da Zona Sul do Rio de Janeiro. Tese de Doutorado não-publicada, Curso de Pós-Graduação em Saúde Pública, Escola Nacional de Saúde Pública, Fundação Oswaldo Cruz. Rio de Janeiro, RJ.

Robazzi, M. L. C. C., Cano, M. A. T. \& Fávero, M. (1996). O trabalho da criança e do adolescente no Brasil: Acidentes ocupacionais e programas de prevenção existentes. Revista Brasileira de Saúde Escolar, 4, 57-59.

Sá, C. P. (1996). Núcleo central das representações sociais. Petrópolis, RJ: Vozes.

Sá, C. P. (1998). A construção do objeto de pesquisa em representações sociais. Rio de Janeiro: EdUERJ.

Sato, L. (1993). A representação social do trabalho penoso. M. J. Em Spink (Org.), O conbecimento no cotidiano: As representaçoes sociais na perspectiva da psicologia social (pp. 188211). São Paulo: Brasiliense.

Vergès, P. (1982). L'évocation de l'argent: Une méthode pour la definition du noyau central de la représentation. Bulletin de Psychologie, 45(405), 203-209.

Vergès, P. (1984). Une possible méthodologie pour l’approche des représentations économiques. Communication-Information, 6(23), 375-398.

Vergès, P. (2000). Ensemble de programmes permettant l'analyse des évocations: Manuel Version 2.00. Aix-en-Provence: Laboratoire Méditerranéen de Sociologie.

Recebido: 07/02/2003

Última revisão: 16/12/2003

Aceite final: $23 / 12 / 2003$

\section{Sobre os autores}

Denize Cristina Oliveira é Doutora em Saúde Pública com Pós-doutorado em Psicologia Social. É Professora Titular de Pesquisa da Faculdade de Enfermagem da Universidade do Estado do Rio de Janeiro.

Frida Marina Fischer é Doutora em Saúde Pública. É Professora Titular da Faculdade de Saúde Pública da Universidade de São Paulo. Mariana Almeida Amaral é aluna de Psicologia. É Bolsista de Treinamento Técnico em Pesquisa da Fundação de Amparo à Pesquisa do Estado de São Paulo (FAPESP); Faculdade de Saúde Pública da Universidade de São Paulo.

Maria Cristina Triguero Veloz Teixeira é Doutora em Filosofia da Saúde, Faculdade de Saúde Pública da Universidade de São Paulo e da Universidade Presbiteriana Mackenzie.

Celso Pereira Sá é Doutor em Psicologia Social. É Professor Titular de Psicologia Social do Instituto de Psicologia da Universidade do Estado do Rio de Janeiro. 